\title{
Communicative and Literary approaches to English Language in the current Textbook of Khyber Pakhtunkhwa, Pakistan, Curriculum
}

\author{
* Muhammad Bilal, Lecturer in English / PhD Scholar (Corresponding Author) \\ ** Syed Qasim Shah, Lecturer in English \\ *** Naseem Ullah Khan, Lecturer in English
}

\begin{abstract}
This study investigates the suitability of literary and communicative approaches in Pakistani course design and revealed the practical problems faced by both teachers and students regarding the use of approaches. The purpose of the study is to provide a textbook that may have both communicative and literary approaches based on the demands and requirements of English in Pakistani territory. Therefore this editorial is an effort to examine the nature of the literary approach in the classrooms of today through the role of the communicative approach. The researcher followed a qualitative approach. One good approach to decide why students at all levels are not able to talk in L 2 is to conduct an in-depth interview of potential participants in the category. Textbooks give a significant contribution in the teaching-learning process both to the teachers and to the learners and provide a system of instruction and orientation along with that a syllabus or course have to preserve language as fundamental phenomena. For this purpose, the curriculum and syllabus designers must head off from that of conventional way or a view concern with literature. This generates a need for textbook adaptation at the activity, unit, and syllabus levels.
\end{abstract}

Keywords: English Language, communication, textbooks, English Teacher, Learner, CLT, ESL Introduction

English serves as a Langue Franca in most countries and is a key to modern science and technology. English Language is used in the country for academic purposes. Official, academic work and documentation are recorded in English in courts, senates, parliament, and universities and are used as a source for Pakistani high-level exams. If a language turns out to be so much indispensable for advancing in both educational and official professions, greater importance must be given to syllabus and course design. English is necessary and it is more important to make progress in both the educational and official professions because it is the most commonly spoken language in the world and is used in various fields such as technology and business, and it needs to be given greater importance in syllabus and course design. The textbook is the syllabus materialization, and the learners take their initial step towards the process of learning the English language. A textbook can either have a communicative or literary style, or it can be a mixture of both the demands and conditions of the English language regarding the Pakistani curriculum. The combination of literary text and CLT, investigate and catch the light, the students' thoughts and creative skills in the basic communication approach that illuminates the purpose of English.

Every human society has its language which is learned in different situations and enhances its capacity in all kinds of situations within its society; such language is called mother tong or native language or L1 which is spoken in a particular region while those languages which are the languages of some other group or nation are called L2 or non-native languages. In the latter case, a language should be taught in an artificial language situation by books and teachers so that the learners can be prepared to handle any language situation. Those languages need to be learned at the national or international level because of their inseparable significance. In the aftermath of England's domination over life's cultural, educational, scientific, and military spares as well as British imperialism and colonialism. English had grown into an international language. It is used not only in international trade, industry, and banking but also in Hollywood, English is the only communication medium. It is

* Bacha Khan University, Charsadda, Pakistan Email: muhammadbilal29@gmail.com

** Bacha Khan University, Charsadda, Pakistan Email: qasimshahpmd@ gmail.com

*** Bacha Khan University, Charsadda, Pakistan Email: naseemduke77@gmail.com 
considered a cornerstone or guarantee of success in the modern world because no accomplishment is possible without adequate knowledge of this language, so in many countries, it has taken part in Langue Franca's prestigious position, or in other words, it has become the medium of communication. It is used in such countries for both academic and official purposes that's why English is the only medium of communication, and nothing is possible without knowing English, which is why countries around the world are promoting and encouraging children to learn this language at the very fundamental level. To this end, they concentrate on syllabus and course development and implementing other modern techniques that may be useful in enhancing student performance in language skills. Being Language Franca the English Language needs to be taught and learned in some artificial environment to equip learners to deal with all kinds of real-life language situations. Language planners adopt various sources to create such an environment in which textbook is the easiest as well as the cheapest of all. The textbook is a collection of different activities and, as suggested by Grave (2000) is used as a formal and standard source of information about the study of a subject and is the most important and accessible tool for teaching and learning. The textbook contains effective lessons and exercises which provide guidance and a structure for teachers and learners. Besides, the textbook is a source of trust and a source of knowledge for both teachers and learners because it is built after the lengthy and long process of choosing, rejecting, and changing various writers' views. Given the utmost importance of the textbook, different scholars around the world believe that the textbook has many benefits for teachers as well as learners. Basturkmen (2010) states that this is the syllabus' representation for it includes the syllabus designer's decisions on what to know and in what order. Comment Radhika O'Sullivan (1991) in the dissertation, under the title "Literature in the Language Classroom", is a concept that focuses on the point of language development and further argues that it is important for curriculum developers to step away from the traditional literature approach. Ming (2011) explores factors in his article "Affecting the Implementation of Communicative Language" that interfere with the implementation of CLT in English classes by EFL teachers. In his work "Why \& Why Not Literature" Mohammad Khatib Allameh (2011) argues that the position of literature is misunderstood, "Whole Literary Involvement" Pakistani textbooks are full of literary genres in this case, but a question arises that what is the matter that the students are unable to speak in English before graduation; while English is a compulsory subject in all grades. Nevertheless, this paper is special because in Pakistani Khyber Pakhtunkhwa textbooks it addresses the combination of both literature and communicative language teaching. A question arises if the textbooks of all grades are so well organized, why the students cannot speak in English after their graduation; the fault lies elsewhere. The paper's goal is to consider policymakers, concentrate on syllabus design, recruiting English Language Teacher, and combine literature and CLT approaches to create the textbook.

The textbook is a kind of road map for teachers and learners, as their aspirations and priorities are known through the textbook. This consists of resources on the language skills and the practices in question. It is with the aid of the textbook that teachers will assess the success of the learners through assessments or evaluation tools provided in the books. In addition, the textbook contains some supporting resources that are beneficial to teachers such as a teacher's guide, cd, worksheets and videos etc. as well as speeding up a language program's pace.

\section{Literature Review}

The textbook is organized taking into account the objectives set out in the curriculum. It leads to the assumption of an unambiguous approach to language and when the most appropriate approach is taken then these goals can be achieved only. In this context, various methods such as the Communicative Approach or Communicative Language Teaching (CLT) are proposed by different scholars at different times. This method originated in the 1980s places greater emphasis on the role of the learners in a language program by allowing them to engage directly in the process of teaching. This approach, in other words, emphasizes active social interaction by CLT Mitchell (1994) rather than the passive role that the learners play. Savignon and Berns (1984) comment that David A. Wilkins was the first to make a significant contribution to CLT by developing his notional syllabus, which gave linguistic function more significance. This method was further developed by Anthony Howatt (1984) who made a clear distinction between teaching the language through formal communication and teaching it through spontaneous language exploration itself. Hymes (1972), Lightbown and Spada (1999); Power, (2003) according to Hymes, the CLT approach strengthens the 
communicative competence of the learners or their ability to communicate their thoughts, ideas, desires, and knowledge effectively to others and to receive those of others in real-life situation. Hedgcock (2002) stresses the need to gain target language linguistic and pragmatic skills. Whereas Kasper (1997) indicates that linguistic and pragmatic skills can only be accomplished by discovery and the use of the language of goal. Richards and Rodgers (2001: 155) consider it to be the most comprehensive approach to make communicative competence the goal of language teaching as well as adopt the procedures necessary to teach the four language skills in which the interdependence of language and communication is recognized. Kalanxadeh and Bakhtiaryand (2011) take a step further and argue that its comprehensiveness makes this approach both in nature and status more distinctive and more successful than the other approaches known and practiced to date.

Huang and Liu (2000), cited in Norouzi Larsari (2011) These scholars delegate the facilitator's role to the language teacher whose task is to create a student-centered classroom where learners are engaged in real-life situations such as language situations so that they may face no communication difficulties. Chapelle and Hegelheimer (2004) believe that one of the most important tasks of language teachers is to prepare learning assignments and specific expectations for the benefit of learners by acquiring the language and realistic skills they are targeting.

In his research' Factors Affecting the Implementation of Communicative Language Teaching in Taiwanese College English Classes, Ming-Chang (2011) stated that the factors influencing the implementation of CLT related to teachers and students, and indicated that the teacher needed training to inspire and engage students in classes. Savvidou (2004) considered that the reasons given for literary language are inadequate for the classroom because of common observations about literature; the reasons for this are the imaginative use of language in the literary genre and a greater effort to understand literary texts as meaning is unraveled from the social context of the learner. Chick et al (2009) concluded that when students face a difficult situation while reading the text or multi-faceted ideas, the teacher may experience them to close down and refuse to attempt to elucidate them. Robson (1989) argued that literature has a great deal of syntactic and lexical difficulties; it can rarely help learners become skilled users of English. Carter (1986) insisted that a natural declaration can be taken as a method in which language and literature instruction are more closely combined, it is generally the case at present that literature would not be out-of-date, or likely discarded by time, because of the "literacy" of its content. Shih (1999) studied the transformation of English courses from conventional to communicative approach, as well as the focus on language usefulness according to the needs of the learners in the Taiwanese community.

From many perspectives, the approach of the researcher in this connection differs from previous researchers on the topic. Most solutions are in one direction or the other, literature and CLT approaches respectively, but the current approach is multilayered and quite visible under the title "Communicative and literary approaches to English in the new Khyber Pakhtunkhwa, Pakistani, Curriculum" textbook. It is about finding out both approaches in KP's textbook, Pakistan's curriculum, and the role of researchers, policymakers, and designers of syllabuses.

\section{Methodology}

For this purpose, the researcher has adopted a qualitative method. One good approach to decide why students at all levels are not able to talk in L 2 is to conduct an in-depth interview of potential participants in the category, for conducting a comparative study of literary and communicative language teaching to investigate the paper's intent. To figure out where the fault lies, in this regard, the two approaches are discussed respectively the literature learning process and the communicative approaches to investigate the real phenomenon.

\section{Discussion}

Review of the Two Approaches to Literary Analysis for Language Teaching

Language is a literary as well as a communication tool, each of which has different goals and teaching schemes, there are many hypotheses about the assessment of such programs. Literary and communicative approaches are used around many language teaching approaches which use these approaches worldwide.

\section{Approach 1: Reader-Response}

This is a process-oriented approach to a work that lays greater stress upon the responsibility of the reader during the teaching and learning process of literature. It provides the learners with an opportunity to include their understanding, feelings, and sensations in the interpretation of a piece of 
literature. Dias and Hayhoe (1984) comment "it is precisely the role of the reader in the act of reading that has not been sufficiently and properly addressed" (p. 15).

In the reading response approach, this problem is handled by giving an active part to the learners in the learning process. In his theory of literary reading, Rosenblatt describes the transactional relationship between the reader and a piece of literary work. As happening in the work of literature take place at a certain time in place, the reaction of the readers to these events differs from person to person based on their interest and experiences. Such personal differences in approach to a work lead to different interpretations of a literary work. In a sense, this approach proves beneficial to learners by simplifying a literary work and connecting it to the personal experiences of an individual. The role of a simplified piece of literature in stirring the background knowledge of the learners that are stored somewhere in their subconscious, enabling them to understand the language of a work as well as to predict the themes of various literary texts can by no means be repudiated.

\section{Approach 2: literary/Communicative Approach}

Human actions occur in different situation which are full of linguistic symbols; is evidence of human actions, from the simplest insight to the most reflective instant of arrant. The root of everything is Literature (Art) and is vital to society because it is the source of language which enables us to communicate better. In this way, it expands the range of understanding in different territories. This approach calls attention to the responsiveness to the language of literature which is the easiest approach for language learners. It assists students' responses with the experiences of literature and considerably easy to get for language learners. In this regard, it describes diverse instruction in a variety of activities which include brainstorming to stimulate conditioned knowledge; to make predictions, constructing plots, rewriting the stories, using close procedures to make practice and comprehend vocabulary, integrate reading to let the student team up with others, to form opinions and elsewhere slot in a spirited debates. In this way, literature is the simplest source of the CLT approach which is best suited in language development skills form side to side discussion, interaction, collaboration, and collective learning. In a situation, the role of the teacher is not so much imposed in interpretation but only to explain difficult and technical terms and to introduce them in a meaningful way, to provide and prepare learners in an appropriate classroom procedure and try to intervene wherever necessary to provide basic information and stimulate the learners.

The literary/communicative approach responds to the needs of language learners in studying literature. The language learner receives skills and techniques to help out access to the text and develop understanding to diverse genres, and may the learners enjoy a piece of literature that has a deep concern in their lives. Therefore, this approach meets the needs of the language learners in a simple and better way thus, the learners communicate in English to enhance their capability and improve language competence. In this way, the learners have to develop the necessary skills of a concerned language while working in a group and become an active learners. In this regard, most educators agree that this approach is motivating because it helps the learners in handling a text in various genres, increases their enjoyment and interest in literature, improve their independence, and improves their language. In this connection, some aspects and reasons have been discussed as follow:

Course designing in Pakistan, its failure to achieve the desired goals and reasons behind these failures

As English serves as Lingua Franca in most of the countries due to its educational, political, and international status, these countries pay full attention to source designing according to their needs and requirement which may either be communicative, literary, or the combination of both. Pakistan too is among the countries where English has been adopted as an educational and official language. English is considered a key to higher education as well as to success in competitive exam and a person is unaware of the practical usage of English cannot imagine of achieving high office, no matter how much intelligent he or she is in other fields of education. Keeping this in view, English is taught as a compulsory subject from grade one up to degree classes, huge amounts are spent every year on course designing and publication of textbooks but sorry to say, all these efforts bear no fruits. English textbooks are modified almost every year to achieve the desired goals with the catastrophic result that the students educated through these books are unable to write or speak a few sentences even after their graduation. The question arises what factors hamper all these efforts and push the students into a closed alley. In this regard, the following factors must be considered important. 


\section{Unawareness of the purpose of the textbook}

The first and perhaps the most important factor is unawareness of the purpose of the textbook on part of the course designers. The textbook is a solution to the problems faced by as well as to course designing for it is designed in the light of the needs of the learners. A typical textbook must contain such steps which may be helpful to the learners in putting a solution to their problems. As English is Langa Franca in Pakistan its major aim is to prepare learners for communication both on a national and international level i.e. its aim is ESP. unfortunately, the course designers are either unaware of the purpose of the textbook and their aims and objectives or they are intentionally neglecting these goals because the English textbooks at all levels are designed in such a way that they do nothing with the improvement of the learners skills and achievement of the desired tasks. It is still ambiguous which approach has been adopted in the preparation of the textbooks for all grades. Both teachers and learners read and reread these books several times but neither the teachers nor the learners are aware of what their purpose is, in teaching and learning these books.

2. The wrong selection of teachers of English

The wrong selection of the English Teachers is a big issue which the government does not take any notice of it and the purpose is baseless at the end. They select specific teachers for science subject which is a good idea, to teach the required subject by a specific subject teacher. But in the case of English, the authority put English in a General category and makes the door open for all other subjects which is the wrong track, to get English Language Purpose. The General test concludes other subjects' specialists to teach English who even do not know the basics of English. In this way, the very foundation of the English Language is wrong at the very basic level. English is needed to be taught by an English Teacher and a Linguist that make the very groundwork for students, to make the way clear for English for Specific Purpose.

3. Wrong approach to teaching English textbook

The second defect lies with the approach to teaching the English textbook for English itself is not science nor is it among the core subjects from the field of law, political science, economics, and so on but a necessary tool for understanding these subjects. So, in many advanced countries, it is designed and taught to fulfill this need. Unfortunately, the English textbook is designed and taught in a way that is in contrast with the goals of teaching English at schools and colleges. An English textbook is designed in the way that is needed for designing a textbook of Biology, Physics, Chemistry, Pak-study and Islamic studies etc. Like these subjects, the English textbook has short questions, long questions, and MCQs which has blunted the communicative skill of the learners because they learn these questions to pass the paper or obtain high marks. Even though a large part of every exercise has been allocated to grammar and literature, but it is only to translate, not for promoting the communicative skill of learners.

4. Wrong method of teaching English textbook, stress on cramming not on communication skill development

The third fact is responsible for the failure of learners to communicate correctly is the wrong method of teaching English textbook. Almost in every school and college, it is believed that the textbook is just a combination of some stories, short essays, and poems collected for translation only. It is read and translated sometimes word by word while the other time sentence by sentence through an indirect method which the learner has to memorize, such method of teaching, no doubt makes the language learning process more difficult. At the end of every lesson, some questions are given which have to be crammed by learners. Although there is a piece of grammar at the end of every exercise but it bears no fruit, for it is out-dated and archaic as well as taught by such teachers whose subject is other than English.

More-over grammar is taught by these teachers in such a way as to be learned by heart than to be understood only to obtain the marks carried by grammar.

5. Wrong paper pattern

To some extent paper pattern is also responsible for the dullness of learners in the field of English language because course designing and paper pattern are indispensable. A textbook is nothing but a key to the paper and the paper is the manifestation of items present in the book. As for as the English paper pattern in KP is concerned, it is always designed as a paper of science and other subjects ought to be designed, for it also consists of three sections, wherein the first section contains 
in MCQs, the second section has short questions as given at the end of every lesson, paraphrase and explanation of the given stanzas whereas, the third section comprises translation from English to Urdu as well as from Urdu to English, an application, story, letter or essay on given topics, which promotes nothing, save cramming. No attention is paid to the development of the four skills of language, although a short piece of grammar is given in the paper but it is too short and impractical to serve as the white stone to sharpen the creative power of the learner.

\section{Approach 3:}

As mentioned above that the current English course, method of teaching and learning the course, paper pattern, method of examination, and selection of teachers for the field almost at every level do not fulfill the needs of learners i.e. they can neither speak nor write correctly or in other words, they are unable to communicate even after the completion of their bachelor and master degrees, there is an intense need of such a course, teaching methodology, English teacher and paper pattern which can equip learners to meet the challenges of the $21^{\text {st }}$ century. The following are the few points that may clear the way to proceed with obvious ideology.

1. Combination of literature and communicative approach, and textbook design like books IELTS and TOFEL.

The two major bodies i.e. textbooks and communicative skills are responsible for formulating and designing the test pattern i.e. Educational Testing Service test to measure a candidate's proficiency level in the English language. The pattern of the textbook is to be designed accordingly, to reflect the daily life use of English in different walks of life: at study, at work, at play, and social gathering. There are two versions of the test that is academic and general and these tests are composed of four sections namely, Listening, Reading, Writing, and Speaking. According to the same pattern, the English Language Teacher teaches the text according to the above-mentioned pattern and a test is conducted to assess a candidate's English Communication skills. They are put into real-life conversation with a real Language Teacher to get their English conversation skills tested.

2. Exam based on the development of the four language skills i.e. reading, writing, listing, and speaking.

On the test day, candidates appear for the Listening, Reading, and Writing tests one after the other in the same sequence, without any break, like that of the IELTS Test pattern. These mentioned components are always taken in the above sequence for granted and the speaking test is conducted as a one-on-one test to assess a candidate's proficiency in English Communication Skills by an English Teacher. In this way, a candidate put to a real-life conversation with an English Teacher to get his/her conversation skills tested, and further, the response of the test taker is recorded for detailed evaluation like that of IELTS. The mentioned test pattern is structured in such a way that it reflects all the related skills; includes Listening, Reading, Writing, and Speaking which is the ultimate purpose of the learning of the English language as a Second Language.

3. Teaching literature through a communicative approach

The communicative approach is based on the idea that language learning successfully comes to communicate real meaning when learners involve in real communication, their natural strategies for language acquisition are used and it allows them to communicate, to learn English Language thoroughly. The classroom activities are guided by the communicative approach, characterized by meaningful and real communication at all levels, as a result, there is more emphasis on skills rather than system. Lessons are more learner-centered, and there are authentic materials to teach and take tests on the above-mentioned way that is IELTS. Classroom reading aims to help the students develop the skills they need to read more effectively in different ways, through this way we plan pre-reading while reading and post-reading stages. The mentioned stages can help the learners to make reading more communicative. Another important point is the pre-reading tasks which raise the reader's knowledge of what they are about to read and help the learners to understand the text in a meaningful way.

\section{Reason and Recommendation}

There are a lot of factors that need to be taken into deliberation context to the textbook adaptation. In response, to make textbooks adequate in many different contexts, controversial topics/subjects are needed to be avoided and present an idealized view of the world. According to the purpose of the English Language in Pakistan, one view has to be adopted which serves the purpose. The Teacher's understandings of how people learn and the students' existing stances towards responsive issues play 
an important role in textbook understanding and alteration. It will help in making decisions, to adopt a textbook at the activity level, unit, or syllabus level. And it is the very essence that the teachers should aware of the beliefs concern with what they know about students and their needs. As in some contexts, teachers have a great deal of independence as far as whatever they do in the classroom, English Teachers should have to be given the place to get EFL purpose in Pakistan. The contents and examples may not be appropriate to the group culturally and they may not mirror the student's needs since the textbooks are written for global markets and do not reflect the interests of the students. They may also contain inauthentic language, text, dialogs, and other aspects of content that need to be written to incorporate teaching points and are not representative of real language use. Sometimes the content may not be the right level and there may not be the right mixture of activities, but the teacher may be too much focused on one or more aspects of language to serves the purpose in the country. The sequence of units may not be following the real work-related needs but English Language Teachers can mold it according to the need of second language acquisition/learning. English Teachers put the students on practical work i.e. writing and speaking in the classroom, only reading and visuals may not serve the purpose. The timetable for completing the textbook may be unrealistic and the focus may be diverting from the real purpose of English language learning. It is an important factor to activate students' plan in reading literature, is important and to make the learning experience personal, will increase students participation and motivation. There is an array of substitutions about how much the textbook has to be adapted. The Teacher may adapt it with different levels, the textbook at the activity level, at the unit level, and the syllabus level. To create the best possible course it is important that the teacher may prefer to ask or judge the learners of L2 to express their views of how effective the textbook and the adaptation are. This activity gives L2 teachers valuable feedback for re-planning and tries to create a connection between the teacher and learners. Each time the L2 teacher goes through the cycle of planning, re-planning, and re-teaching can make easy choices about what to emphasize, what to leave about, where to supplement and personalize the textbook.

\section{Conclusion}

Consequently, textbooks give a great contribution to the teaching-learning process of both the teachers and the learners and offer a framework of guidance and orientation along with that a syllabus or course have to maintain language as a fundamental phenomenon. For this reason, the curriculum and syllabus designers must head off from that of traditional way or a view concern with literature. The strategies to recruit an English Teacher (Subject Specialist) have great importance along with syllabus designing and the goals and objectives may draw around the significance of literature in the direction of language growth. However, apart from the plentiful advantages of a text but a single textbook frequently does not meet the diverse needs of the learners. This generates a need for textbook adaptation at the activity, unit, and syllabus levels. Adaptation of such an approach provides teachers with an opportunity to make greater use of their professional skills and for learners to be involved in the learning process.

\section{References}

Basturkmen, H. (2010). Developing Courses in English for Specific Purposes. New Your: Palgrave Macmillan.

Carter, A. (1986). "Linguistic Models, Language and Literatiness." In R.Carter \& G.J. Brumfit (ed) Literature and Language Teaching. Cambridge: Cambridge University Press, pp. 110-132.

Grave, K. (2000). Designing Language Course, A Guide for Teacher. Boston. Heinle. Cengage Learning. Graves, K. (1996). Teachers as course developers. England: Cambridge University Press.

Hedgcock, J. (2002). Facilitating access to communities of practice in language teaching: Toward a sociolieratere approach to teacher education. . Asian EFL Journal.

Howatt, A. (1984). A history of English Language Teaching. . Oxford: Oxford: University Press.

Hymes, D. (1972). On Communicative Competence. . J.B. Pride \& J. Holmes (Eds.) Sociolinguistics (55-67) Harmonds Worth, England: Penguin Books.

Kasper, G. (1997). Can pragmatic competence be taught? Second Language Teaching and Curriculum Center. Retrieved November 2, 2004, from http://nflrc. hawii.edu/Networks/NW06/ default.html.

M, S. S. (1994). Initiatives in Communicative Language Teaching: Reading. . MA: Addison-Wesly. 
Ming, C. (2011). Factors Affecting the Implementation of Communicative Language Teaching in Taiwanese College English Classes. Ccsenet, Taiwan. Vol. 4, No. 2; June 2011.

Mitchell, R. (1994). The Communicative Approach to Language Teaching. New York: Routledge.

Mohammad Khatib, A. D. (2011). Why \& Why Not Literature: A Task-Based Approach to Teaching Literature. International Journal of English Linguistics.

Chick et al. (2009). Pressing an ear against teh hive: Reading literature for complexity. Pedagogy, 9(3), 399-422.

O'Sullivan, R. (2017). Literature in the Language Classroom. Universiti Kebangsaan Malaysia, Kuala Pilah.

Power, T. (2003). Communicative Language Teaching: The appeal and poverty of Communicative Language Teaching. . TESOL Quarterly.

Robson, A. E. (1989). The use of literature in ESL and culture-learning courses in US colleges. TESOL Newsletter, 23, 25-27.

Savvidou, C. (2004). An Integrated approach to teaching literature in teh EFL classroom. The Internet TESL Journal, X No. 12, [Online] Available: http://iteslj.org/)April, 2010).

Shih, M. (1999). More than practicing language: Communicative reading and writing for Asian settings. TESOL Journal, 8(4) 20-25. 